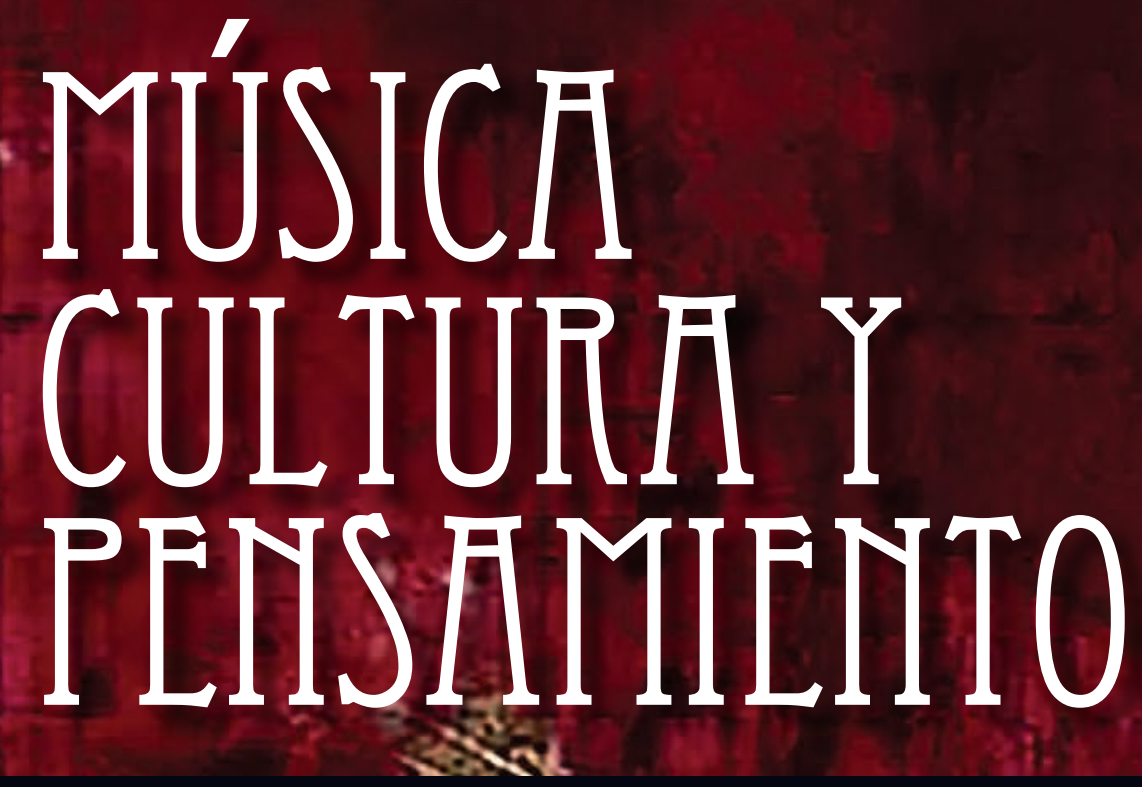

Revista de investigación de la Facultad de Educación y Artes del Conservatorio del Tolima

VOL. VI N.॰ 6 - Noviembre 2017

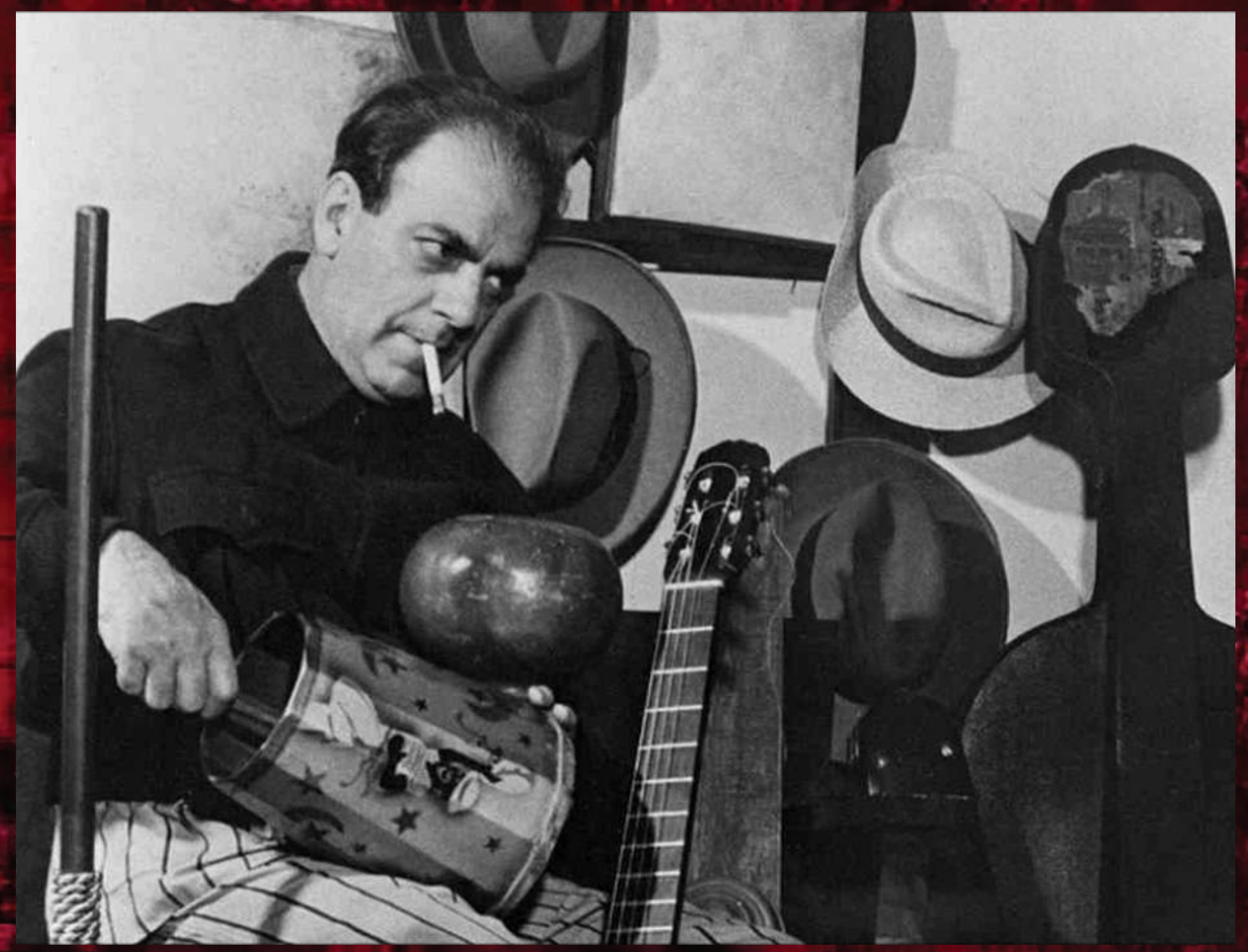




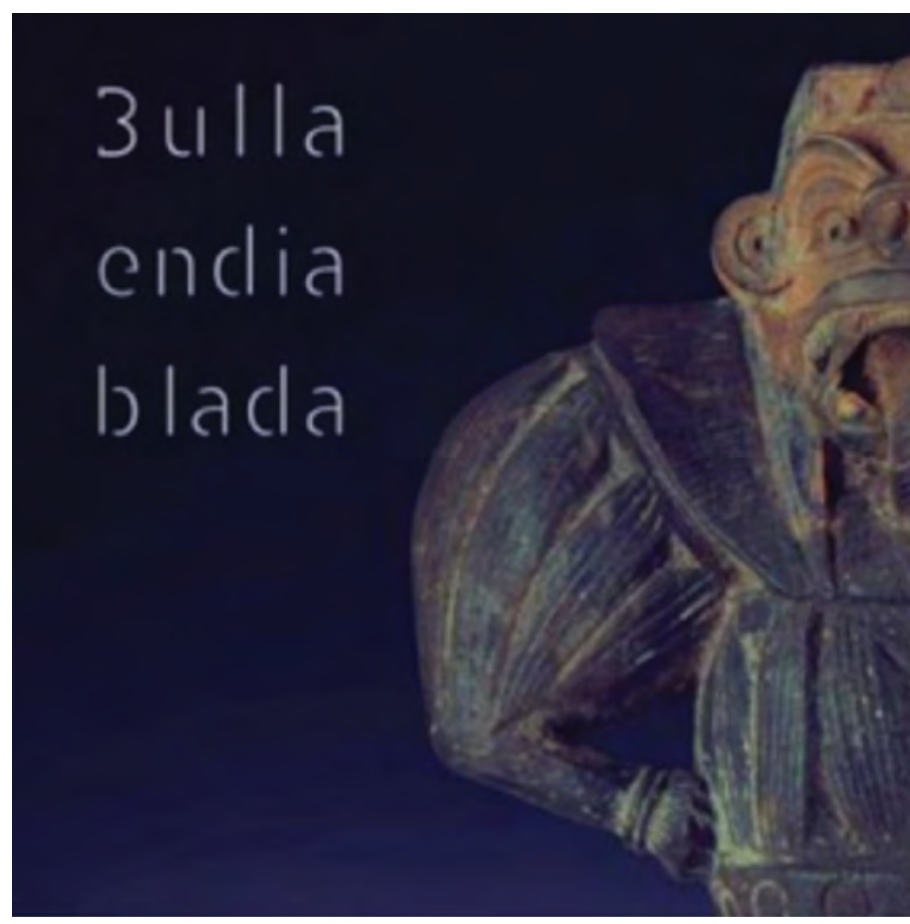

\section{Bulla Endiablada}

José Agustín Cárdenas y Luis Fernando Franco Duque Ministerio de Cultura, Museo Universidad de Antioquia, Medellín, 2014, 65 pp., fot.; 21 cm + CD

\author{
Por: Humberto Galindo \\ Profesor Asociado \\ Facultad de Educación y Artes \\ Grupo de investigación Aulos \\ Conservatorio del Tolima \\ Ibagué, Colombia \\ Correo electrónico: \\ humberto.galindo@conservatoriodeltolima.edu.co
}

\section{Música y arqueología en Colombia: en busca de audiencias}

La publicación por parte del Ministerio de Cultura y el Museo de la Universidad de Antioquia de Bulla Endiablada (libro y CD), es una novedad dentro del catálogo de trabajos recientes en los que música y arqueología se encuentran para abordar el tema de los instrumentos musicales prehispánicos en Colombia. La edición corresponde al trabajo colaborativo de José Agustín Cárdenas Bedoya, antropólogo de la Universidad de Antioquia, y Luis Fernando Franco Duque, compositor y productor musical, quienes conjugan dos disciplinas en las que se esperaría en Colombia contar con una mayor dinámica de trabajos publicados, habida cuenta del rico patrimonio de "artefactos sonoros prehispánicos" que se conservan en museos y colecciones privadas actuales en nuestro país, como testigos mudos de la memoria cultural indoamericana ${ }^{1}$

Sus autores cristalizan este trabajo a partir de una selección de ocarinas de la cultura tairona, de la colección de Antropología del Museo de la Universidad de Antioquia (MUUA), instrumentos que fueron objeto de estudio de la tesis de grado de José Agustín Cárdenas y la temática de un concierto realizado en 2007. El libro en edición de lujo de pequeño formato, ilustrado con los instrumentos utilizados en la producción sonora, explica su contexto antropológico, especificidades morfológicas y acústicas. Por otra parte, el CD presenta la experimentación creativa del compositor con los sonidos de dichos instrumentos, a partir de su acercamiento "intuitivo [...] mediante la impro-

1 Entre otros textos de referencia para ampliación del tema, ver los siguientes: Luis Antonio Escobar, La música precolombina, 1985, Bogotá, Universidad Central; William Duica, La música de la vida, catálogo de exposición, 1991, Bogotá: Banco de la República; Emiro Reyes, "El papel de las TIC en la recuperación de sonidos de instrumentos prehispánicos", en Música, cultura y Pensamiento, No. 3, 2011, Ibagué: Conservatorio del Tolima; Germán Pinilla, Adriana Guzmán y Juan Camilo Buitrago, Sonidos de barro: análisis de instrumentos sonoros de las culturas prehispánicas Tumaco - La Tolita, Tuzca y Piartal, 2010, Cali: Universidad del Valle [CD con cuadernillo]. 
visación musical [...] desde un universo sonoro [...] valioso y suficiente por sí mismo" (p. 59).

\section{Los instrumentos y su relación sonora mítico-ritual}

La primera sección describe la significación de estos instrumentos dentro del universo cultural mítico-ritual de las comunidades indígenas tairona de la Sierra Nevada de Santa Marta, elemento común en la música de otros grupos indígenas como los uitoto y muinane del Amazonas, como lo muestran los autores. A partir de allí, se conduce a la explicación sobre la conexión orificio - sonido - soplo presente en las ocarinas en su relación con el mito, cuya sonoridad extraña para el oído de los primeros misioneros y conquistadores fue acuñada como una bulla endiablada, término que da nombre a la producción y que, como lo expresan sus autores, no es otra cosa que "un mar de sonidos al que hay que descender para extraer algo probablemente perdido, para recuperar una experiencia remota, una memoria silenciada" (p. 20).

En el capítulo siguiente, los autores presentan como preludio y fuga las disertaciones musicales, antropológicas y arqueológicas profusamente apoyadas en distintas fuentes como Reichel Dolmatoff (1985), Chumeil (2011) y Carlos Vega (1989), para dar cuerpo teórico-argumentativo al discurso musical propuesto en el trabajo creativo, que de alguna manera prepara al oyente para percibir un material sonoro no temperado al oído occidental en su búsqueda por evocar "las densidades sonoras propias de las músicas indígenas" (p. 59). Las fotografías ampliadas a color de los instrumentos vienen acompañadas de sus respectivas fichas con la descripción de origen, dimensiones, material, técnica de construcción, cronología y en particular, la información del instrumento respecto a su acústica, con lo cual se da al lector una aproximación completa del objeto, más allá de los aspectos puramente arqueológicos que habitualmente informan las fichas de los museos.

A partir de la página 35, las descripciones y fotografías incorporan las referencias a las grabaciones del CD anexo. Así por ejemplo, la ocarina tairona en forma de ave, con registro MB0580, perteneciente a la zona Guachaca, Santa Marta, Magdalena, cuyas dimensiones son $4,8 \times 6,5 \times 5,7 \mathrm{~cm}$, produce catorce sonidos diferentes $y$ se puede escuchar en el audio No. 3 titulado Soplo de tabaco, que el compositor Luis Fernando Franco propone en el primer grupo denominado "Los Permisos".
Se complementan texto y audios con las siluetas de digitación de las ocarinas y los diagramas de medición de su onda sonora, que revelan algunas particularidades como la complejidad estructural en este tipo de instrumentos y la presencia del trisonido, producido por cámaras internas que "generan desde la práctica musical, una exagerada disonancia” (p. 39)². Para completar la información técnica, se suministra en la página 62 una tabla resumida de las catorce ocarinas utilizadas en el proyecto, indicando sus registros sonoros mediante una nomenclatura americana de las notas musicales ( $\mathrm{C} 3=$ do central), complementada con otros signos (+, -) que buscan informar al lector sobre las alteraciones de los registros respecto a la afinación temperada occidental (variaciones de $1 / 4$ y $1 / 8$ de tono).

\section{Creación - experimentación musical a partir de instrumentos arqueológicos}

Pasando al contenido del CD, se presenta su índice en la contratapa del libro, organizado en seis grupos a manera de movimientos que reúnen el total de 27 motivos musicales propuestos por el compositor: i) Los permisos (Aluna -antes del amanecer-, Bulla endiablada, Soplo de tabaco, Bienvenidos a la fiesta): ii) La travesía (Guacharacas, La otra orilla, Manglar, Río abajo); iii) Monte adentro (Culebra, Matorral, El cerro); iv) Bandadas (Reencuentro, Ascenso, Maukui, Bandada, Luciérnagas, Pájaros nocturnos); v) El viento (Hoja de coca, Abejas, Cenizas, Mambe, Brisa, Heiséi -máscara de tigre-); vi) El retorno (Arrojo, Sewa -seguranza-, La paguana, Nacimiento).

Al escuchar el conjunto de motivos musicales se hace evidente la intencionalidad del compositor para crear distintos climas armonizando polifónicamente el sonido de las ocarinas con percusiones propias

2 Sobre la presencia de estos trisonidos en instrumentos de culturas prehispánicas se pueden consultar particularmente los trabajos de inventario sobre colecciones de México, Perú y Chile. Uno de ellos es el proyecto Achalai, donde se evidencia el uso de cámaras y tubos complejos en algunos aerófonos andinos. Ver: Lina Barrientos y José Pérez de Arce. (2013). Acciones de Achalai para la recuperación del patrimonio sonoro musical prehispánico. Rev. Music. Chil., 67(219). Recuperado de http://www.scielo.cl/scielo.php?script=sci_arttext\&pid=S0716-27902013000100004. Jose Pérez de Arce. (2015). Flautas arqueológicas del Ecuador. Resonancias, 19(37), 47-88. 
de la región Caribe, que logran un recorrido musical variado y fluido, explotando al máximo los rangos y colores tímbricos de estos aerófonos, sin pretender en ningún momento abordar una reconstrucción del pasado sonoro prehispánico, con lo cual queda claro el interés principal de captar audiencias amplias de este contenido, que de otro modo bien podría quedar restringido a los pocos especialistas para su discusión desde la arqueología asociada, la físico acústica.

\section{Conclusiones}

Visto en su conjunto, el producto editorial - sonoro de Bulla Endiablada hace un aporte que nutre la escasa producción de materiales de este tipo en nuestro país, al lograr desde su impecable edición dirigirse a un público amplio, sensible a patrimonios culturales únicos como los que se conservan en el Museo Universitario Universidad de Antioquia. A su vez, logra proponer un discurso antropológico y musical creativo dirigido a la comunidad académica en un tema tan particular y especializado, del cual el referente más cercano, titulado Sonidos de Barro (Pinilla, Guzmán y Buitrago, 2010), fue publicado en 2010 por el Museo Arqueológico de la Universidad del Valle ${ }^{3}$. El interés por la arqueología musical que ha motivado la producción de Bulla Endiablada tiene antecedentes en nuestro país y en Latinoamérica, y plantea varias inquietudes latentes entre las entidades museales, las universidades y sus investigadores, respecto a la necesidad de conformar redes de trabajo interdisciplinario entre arqueología, antropología y musicología, para documentar de manera integral el patrimonio sonoro prehispánico representado en colecciones y exposiciones museales del país y así cumplir a cabalidad, como bien lo indica Santiago Ortiz, director del MUUA, con el compromiso ético del museo "por salvaguardar, proteger, recuperar, conservar y divulgar creativamente los referentes de identidad del país de manera directa en los distintos públicos del país y de otras latitudes" (p. 15).
3 A diferencia de Bulla Endiablada, Sonidos de Barro es un $\mathrm{CD}$ didáctico y multimedia, producto de una investigación arqueológica de un equipo multidisciplinar, que acompaña una exposición de cerca de cincuenta objetos sonoros arqueológicos estudiados, que incluyen caracoles, silbatos y ocarinas. Con un enfoque más científico, este trabajo informa sobre la cartografía de los hallazgos arqueológicos y mediante tomografías, escáneres y dibujos, revela la estructura interior de los instrumentos, la manera como se tocan los instrumentos, explicando sus sonidos desde la notación musical convencional y precisando las distorsiones tonales del sistema mediante datos en hercios $(\mathrm{Hz})$. 


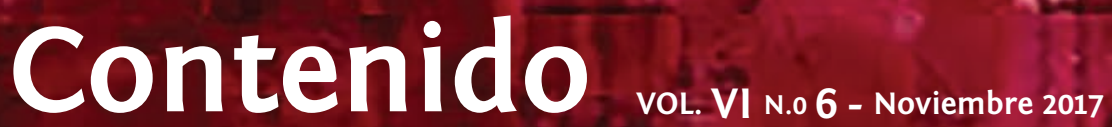

\author{
4 \\ 5 Editorial \\ Música y Cultura \\ Índices Revista Música, Cultura y \\ Pensamiento \\ Humberto Galindo Palma \\ 52 Música en Clave \\ propuesta de reedición e interpretación \\ Cristhy Alejandra Hoyos López, \\ Julián David Quintero Guzmán
}

Convocatoria Revista N. ${ }^{\circ} 7$

\section{Música y Pensamiento}

46

El piano y la niña del conservatorio Jaques Dalcrozze,

Juliana Pérez González (traducción)

\section{4}

\section{Reseña}

Música y Arqueología en Colombia, en busca de audiencias

Humberto Galindo Palma

\section{Separata}

Delirio de Amor Op. 19

Eugenio Zamora García

Asobbio a Játo

Heitor Villa-Lobos 